\title{
An Analysis of Driving mechanism of Enterprise Management Innovation Based on Lean Thinking
}

\author{
Shuwei Jing ${ }^{a}$, Zhanwen Niu ${ }^{\text {b }}$ \\ College of Management and Economics, Tianjin University, Tianjin 300072, China. \\ ajingshuwei.abcd@aliyun.com, bzw.niu@163.com
}

Keywords: lean thinking, enterprise management innovation, innovation mechanism, case study.

\begin{abstract}
With the method of case study, implementation of lean management in four enterprises, FAW Car Company (FAW), China International Marine Container (CIMC), Junlebao Diary Co. (JLBC) and Tianjin General Water Co. (TJCGE), are analyzed in this research. It is concluded that lean thinking drives enterprise management innovation by acting on management idea, management culture, management method, management organization, management institution, performance management, business model and market innovation. Acting mechanism between lean thinking and enterprise management concept, organization, method, culture, system, market, business model, etc. is also clarified, which provides valuable reference for lean practice in enterprises.
\end{abstract}

\section{Introduction}

The lean thinking with total involvement, continual improvement, eliminating waste, creating value, stimulating the positive energy as its core, provides an effective way to solve the problems occurring during the intranet development, as well as introduces a totally new way to drive the enterprise innovation [1]. Some typical cases of lean management practice including Toyota Production System, Hongqi Production System and CIMC's ONE Model have shown the world how lean thinking plays an important role in enterprise management innovation. However, researches aimed to find out how lean thinking works in driving the enterprise management innovation or what contents lean thinking works on are in short in spite of a large amount of contents are included in the enterprise management innovation [2].

To figure out those questions, for one hand, it drives the theory of enterprise management innovation by broadening the span of lean thinking management. On the other hand, it offers enterprises with directory guides in lean practice, therefore pushing enterprise management innovation forwards efficiently. Based on this, the research is focused on the driving mechanism that lean thinking works on the enterprise management innovation.

\section{Analysis Framework}

Enterprise management innovation, which is advanced for a more effective utilization of resources and the promotion of organization efficiency, to reach the fixed target made by organization system, will finally bring about an effective reform in the enterprises' original management activity or process. It's an exploration in management approaches in enterprises which are chasing brilliance. It's comprised mainly by management idea, management organization, management method, management culture, management institution, market innovation, business model and performance management[3].

It's generally accepted by scholars that lean thinking has an important drive on promote ability of enterprise management innovation. Existing literatures have also done research on lean thinking, management innovation of literature and their relation. Though this research isn't in a deep-going way, it lays the foundation of the possibility to find out the driving mechanism that lean thinking works on enterprise management innovation. For one thing, existed research analyzes the driving mechanism of enterprise management innovation, but ignores the specific innovation facets. That's because existed research believes there are 8 main aspects, whose mutual driving mechanism should 
be figured out before driving mechanism of innovation itself. For another thing, both the existing research and practical work in enterprises show that lean thinking greatly drives enterprise management innovation, but don't tell how this drive works, or by what specific functions to finally raise the level of innovation. To answer questions above, this paper proposed the analytical framework as Fig 1.

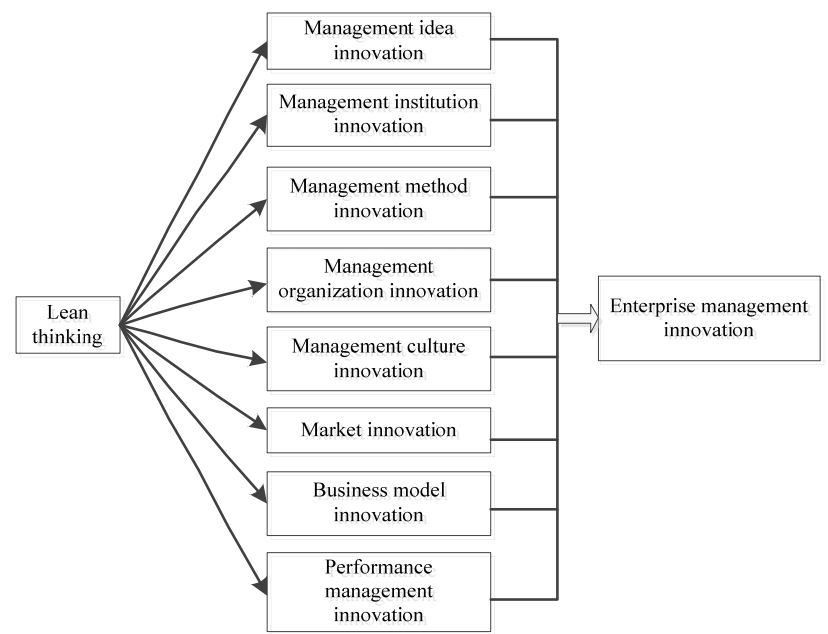

Fig. 1 Analysis framework

\section{Research Design}

According to the sample selection rules in multiple-case study, we use cases of practical leaning management in four enterprises, FAW, CIMC, JLBC and TJCGE, as samples in this research, because these cases reflect the application and development of lean in Chinese enterprises. FAW Car Company represents the lean practice in automotive manufacturing industry, also the birthplace of lean practice among whole Chinese enterprises. CIMC is the first company to successfully apply the lean practice in more fields of manufacturing industry, not only the automotive industry. JLBC and TJCGE are the representatives of the lean usage in manufacturing service enterprises, in addition to fields of manufacturing industry. All the data used in this research are collected according to interview $[4,5]$.

\section{Case Description}

FAW was established in 1997. Since 1998 FAW has been learning APS. Until 2002, the production and sales fluctuated between 10,000 and 20,000. Lean management was introduced in 2002, when external environment and market competition were increasingly fierce. In 2003, FAW started cooperation with Mazda to learn MPS and it has reached a milestone. From 2003 to 2006, the production and sales remained between 50,000 to 60,000. After 2007, new explorations of management innovation system gradually started and finally formed a specific one in 2012.

Since establishment in 1980, CIMC, the globally largest manufacturer of containers, has dedicated into manufacturing and service of transportation and energy equipment. While the financial crisis in 2007 threatened CIMC. To better adapt to the era, CIMC started implementation of lean management in a full scale. The management mode for upgrading capability was formally raised in March, 2008.

Launched in 1995, the major products of Junlebao were yogurt series, cheese series and active milk beverage. Lean management was introduced in a pilot way, aiming at strengthening the brand building, creating high-end products and meeting high requirements of industry. Until 2013 dramatic improvements have been achieved in production field and staff accomplishment.

Affiliated to TJCGE and operating since 1963, the water supply capacity is 500,000 ton per day after expansions for two periods. The company, with a history of more than a half century, encounters headaches like other senior state-owned ones, specifically, aging among staff, lack of enthusiasm, disorganized field and extensive management, etc. these have been severely impeding the 
development of the company. To tackle with these problems, lean management was introduced in May, 2013 with great support from the Group. The template department got improved and the enthusiasm was greatly enhanced.

\section{Case Discussion}

Lean Thinking and Innovation on Management Idea and Management Culture. When lean is introduced as a new kind of management thinking, it firstly creates atmosphere in relation with management idea and culture, which helps preliminary realization of innovation in management idea and culture. The driving mechanism is shown in Fig.2.

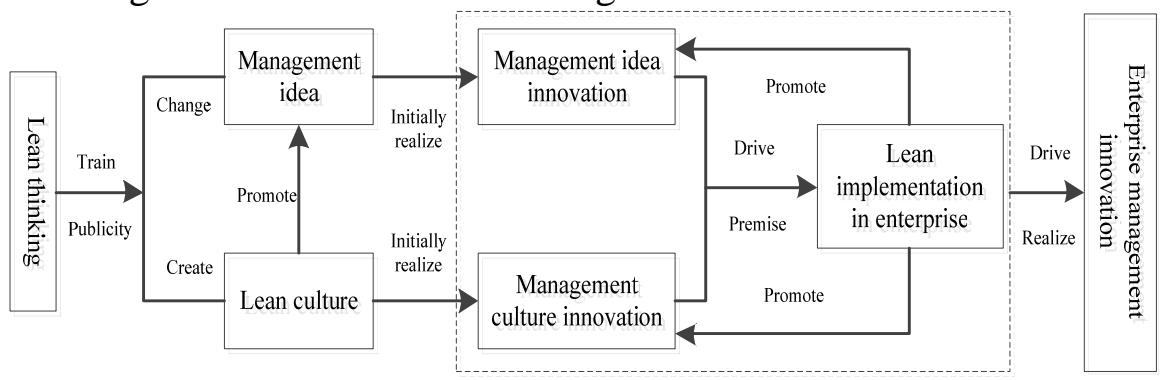

Fig.2. Driving mechanism of management idea innovation and culture innovation based on lean thinking

Lean Thinking and Innovation on Management Methods and Management Organization. Enterprise starts to apply lean implements and methods to search for would be improving points for the next improvement on the basis of a first realization of management idea by lean training and propaganda, and adjusts the organization structure through establishing operation standards and optimization the management procedure. The driving mechanism is shown in Fig.3.

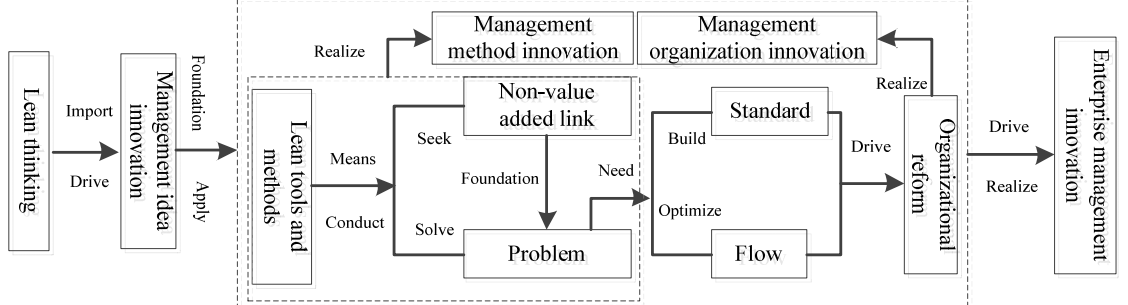

Fig.3. Driving mechanism of management method innovation and organization innovation based on lean thinking

Lean Thinking and Innovation on management institution and performance management. In the process of lean practice, considerable management systems are established and optimized in order to improve continually and solidify the effects which also results in management innovation; at the same time, to arose the enthusiasm of the employees and realize the total involvement, incentive and performance appraisal system are also established and optimized step by step in the process of implementation, pushing the management innovation continually. The driving mechanism is shown in Fig.4.

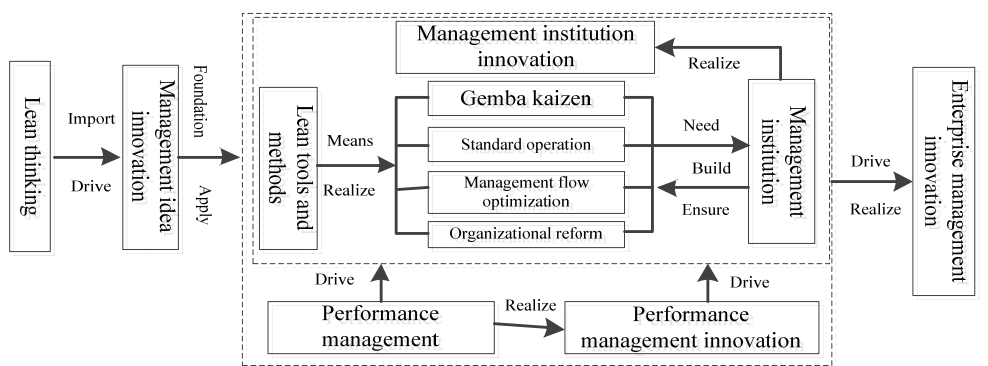

Fig.4. Driving mechanism of management institution innovation and performance management innovation based on lean thinking

Lean Thinking and Innovation on business model and market. Business model and market are the results of applying management thought therefor business model innovation is fulfilled based on 
optimization of internal management process, mainly through developing operation model of logistics, information flow and fund flow between consumers, suppliers and other partners and establishing lean, steady business model. The driving mechanism is shown in Fig.5.

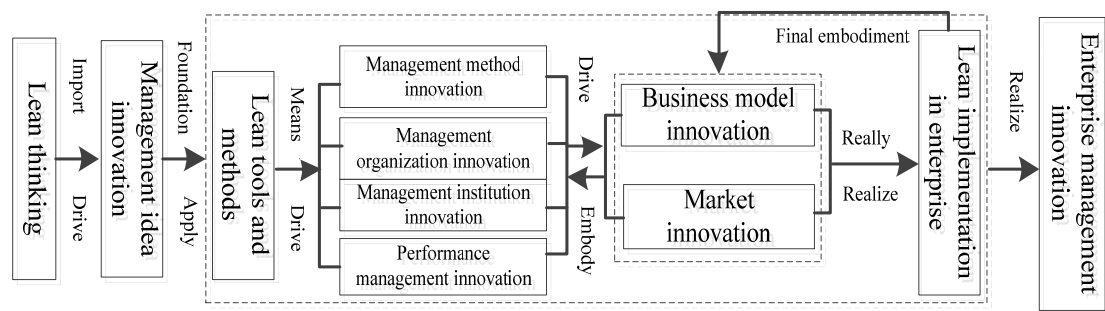

Fig.5. Driving mechanism of business model innovation and market innovation based on lean thinking

\section{Conclusion}

Lean thinking working on the management idea and culture innovation is the basis of promote innovation of other aspects, as well as enterprise management innovation. After the enterprise introducing the lean thinking, and realizing the preliminary innovation on management concept and management culture, such lean implements and methods which is used to realize management method, management organization, management institution, and performance management will be applied for further promoting enterprise to build up a lean business model and discover new markets. Business model innovation and market innovation are the reflection of lean putting into reality in enterprise, which is also the main purpose of enterprise management innovation. The innovation on management institution and performance management is the guarantee of enterprise continuous innovation. At the same time, by the continuous promotion of lean, the lean thinking will be solidified in the enterprise in term of the culture, which bring the enterprise long-term management innovation plenty vitality. This conclusion has shown the driving mechanism that lean thinking works on enterprise management innovation. Also, it provides basis and reference for enterprise improving their level of management innovation by lean.

\section{Acknowledgment}

This research was supported by the National Natural Science Foundation of China under grant no.71071107.

\section{References}

[1] M. Hoss, C. S. Caten, Lean schools of thought, International Journal of Production Research, 51 (2013) 3270-3282.

[2] Z. W. Niu, S. W. Jing, Discussion on management innovation model of manufacturing enterprises based on lean production, Journal of Tianjin University, 16 (2014) 481-487.

[3] M. J. Mol, J. Birkinshaw, The sources of management innovation: When firms introduce new management practices, Journal of Business Research, 62 (2009) 1269-1280.

[4] K. Xu, L. Tihanyi, M. A. Hitt, Firm resources, governmental power and privatization, Journal of Management, 40 (2014) 1-27.

[5] M. C. Minano, J. M. Fuentes, M. S. Diaz, What can we learn from the evolution of research on lean management assessment, International Journal of Production Research, 51 (2013) 1098-1116.

[6] R. K. Yin, Case study research: Design and methods, fifth ed., SAGE Publications Inc, America, 2014. 